\title{
Construct Validity for Measuring Entrepreneurial Readiness Among Malaysian Higher Education Students: A Stochastic Measurement Model Approach
}

\author{
Jusoh, M.S., PhD, Hj Din, M.S., PhD, Hazliza \& D., Suriani, T. \\ School of Business Innovation and Technopreneuship, University Malaysia Perlis (UniMAP)
}

\begin{abstract}
Instrument construct is one of the most important issues in conducting research. Without proper consideration in tackling the issue, it is difficult for the instrument to be considered as valid and reliable. If construct validity is accurate, then it will provide a clearer and more precise descriptive analysis on the concepts being investigated. The most important criteria that need to be considered in answering the construct validity are reliability and validity. In traditional measurement model, the understanding of reliability and validity is totally different from the one offered by Rasch model. Regardless of the difference, an internal consistency is still widely being used as the primary method to measure the item sampling. Using this model, local dependence and item fit are most considered in getting valid, reliable, and consistent, hence its significance. Finally the study applies goodness of measure purposely to answer issues related to validity and reliability tests. Principal components analysis was carried out to test the construct of questionnaires used in the study.
\end{abstract}

\section{Introduction}

Reliability relates to ability of a measure to remain the same; consistently over time (Sekaran, 2003) or the same result is obtained when the same research is repeated or does it again once more. In order to get the reliability of the test, Cronbach $-\alpha$ is used as the common value in estimating the internal consistencies of the items (Onwuegbuzie \& Danial, 2002). The Cronbach- $\alpha$ value should considerably be higher than the acceptance level of 0.60 (Garson, 1998; Gliem \& Gliem, 2003; Leedy \& Ormrod, 2005) to be taken as reliable. Rasch Analysis further provides the reliability of person and item arising from the interaction between both subjects in the test. If the Person reliability registered 0.76 , it is described as 'Fair' reliability (Fisher Jr., 2007; Azrilah, 2010). This indicates that, the Person in this assessment with reliability equal to or greater than 0.6 , given another set of questionnaire, they stand a high chance to produce a repeat outcome for the next time (Andrich, 1988). Azrilah (2010) further explained, if the selected group of respondents were to be given a different set of quality management-cost of quality-organizational performance tool or questionnaire with the same dimension, the probability of the ability pattern (in person measure order table) or the location of the quality managementcost of quality-organizational performance on the person-item distribution map would remain similar.

The purpose of having validity is to make sure the instrument in use is measuring what it is supposedly to measure (Sekaran, 2003; Zickmund et al., 2010). The criterion validity of such findings represents the actual likeliness of the situation. Since most of the questions were adapted from previous studies, the issue of face validity is to assure the meanings of the questions given are measuring the underlying concept (Sekaran, 2003).
Though some researchers believed that face validity is not a valid component of content validity, it remains a very important process to determine the suitability of the questions given posted to the respondents. The content validity itself has to be done as it will ensures the questionnaire include the adequate and represent or sufficient and enough items to represent the subject matter or the concept ushered in the study (Sekaran, 2003). This will later be validated by the model hence answering the content validity issue. Similarly with the item reliability provided, it will determine whether the instrument is having sufficient number of questions for all range of respondents.

The Rasch's generate important information about the items whether it is measuring in a single direction or behaving erratically by functioning in the opposite direction. In this case, it can be reported that the instrument is behaving in bi-direction. Rasch 'zero-set' the instrument when the item is at a threshold point equals to mid-point 0.5 hence a situation of 50:50. Then, it calibrating the rating scale to ascertain the assumed rating is valid for use. If the threshold separation between any two ratings is less than 1.4, then the assumed rating is collapsed and re-calibrated to ensure better Infit Standard Deviation or invariance obtained. This is the crucial test involve as the procedures itself determines the reliability of the respondents and construct validity of the instrument hence valid data (Andrich, 1988; Bond \& Fox, 2007; Fisher Jr., 2007; Linacre, 2008).

There are three indicators need to be fulfilled before one can claim that the instrument employed, i.e. the questionnaire as reliable and valid thus replicable and measuring what we are supposedly to measure. The explanation summarized by Azrilah (2010):

a) Cronbach- $\alpha$ value (should be more than 0.6)

b) Item Reliability value - to answer whether the question is valid or not. If the reliability value is $>$ 
0.6 ; then the questions asked in the study is sufficient for the expected range of respondents. If the score is less than $<0.6$, then the number of questions asked is insufficient thus invalid instrument construct.

c) Person Separation value - to show the ability of the instrument to discriminate the respondents into distinct groups. If the instrument cannot separate the respondents as expected, then the items need to be reviewed; either rephrased or new item added.

d) Person Reliability value - gives an indication of the person latent trait measures or psychometry. If the score $>0.6$ meaning the person involve in the study is reliable and if the score $<0.6$ meaning that the person is not reliable. Meaning that if the result shows high reliability, it means that the location of person along the ruler will be the same for the second time if an instrument of the same construct were taken by the same respondents.

\section{Measuring Reliability and Validity Using Rasch Measurement Model}

Goodness of measure is performed in answering the issues related to validity and reliability tests. Principal Components Analysis (PCA) was carried out to test the uni-dimensionality of the questions used in the study. Basically the purpose in Rasch is to "perform a Principal Components Analysis of the residuals by item correlation matrix. The first factor reported here is really the second factor, because the Rasch dimension is the first factor overall. This second factor identifies the strongest pattern in local dependency among the items as reflected in their correlations "(Wright, 1996). However, Sick (2011) views Principal Component Analysis as "an extension of Rasch fit analysis used to confirm whether the Rasch difficulty dimension; (thus the construct) has adequately accounted all of the nonrandom variance in the data".

As the items represent in this study fit the model then it supported the unidimensionality of the scale hence explain the goodness of content validity (Wright, 1996; Sick, 2011). Principal Component Analysis allows the researcher to refine the instrument construct further by conducting the process of elimination to choose which item fits best by looking at the item quality compliance. Hence, it allows only quality items to best describe the variables being used.

Tennant and Pallant (2006) further details the Principal Components Analysis capabilities to support the post-hoc testing, having undertaken the Rasch analysis and supposing fit the Rasch model requirements. Principal Components Analysis constituted of two major steps, started with choosing the item fits best from the Local Item Dependence (LID) requirement and the quality compliance to Item Measure standard. Yen (1993) and Zenisky, et al. (2003) suggested using the local item dependence is to detecting the dependency between pairs of items or persons.
In order to select the relevant items to represent the construct, a criterion for local dependence loading had been discussed by few authors. Yen (1984) and Yen (1993) suggested a small positive adjustment to the correlation of size $1 /(\mathrm{L}-1)$ where $\mathrm{L}$ is the test length. Local dependence would be large positive correlation, with highly locally dependent items (Correlation > 0.7) suggesting that only one of the two items is needed for measurement based Table Principal Component Analysis : Largest Standardized Residual Correlations in Winsteps 2006 (Wright et al., 2000).

Further analysis in fulfilling the Rasch criterion through misfit analysis will show the items that are inconsistent with the construction of a single measure. The first step involve in this process is sharing more than half of their random variance (Wright, 1999). As suggested by Wright (1999), the only one of these two items is needed for measurement thus one of the items has to be discarded or removed. Item from the same domain which exhibit measure of MNSQ further away than 1 and the z-Std further than ' 0 ' shall be dropped. Further justification by Tennant and Pallant (2006) suggested, the analysis of the residuals was conducted in detecting the second factors after the Rasch factor is removed due to understanding that, "originally interpretation of this was difficult as the proportion of variance attribute to the first residual factor was reported but the total variation in the data was unknown". Subsequently, Linacre (2006) had incorporated the total variation into presentable and understandable reporting as shown in Table 1.

Table 1: Principal Component Analysis of Standardized Residual variance (in Eigenvalue units)

\begin{tabular}{l|c|c}
\hline & Observed & Modeled \\
\hline Total raw variance & 266.3 & $100.0 \%$ \\
in observations & $100.0 \%$ & $32.4 \%$ \\
Raw variance & 86.3 & $4.8 \%$ \\
explained by & $32.4 \%$ & $27.6 \%$ \\
measures & 12.7 & $100.0 \% 67.6 \%$ \\
Raw variance & $4.8 \%$ & $11.9 \%$ \\
explained by & 73.6 & $7.9 \%$ \\
persons & $27.6 \%$ & $3.8 \%$ \\
Raw variance & 180.0 & $3.6 \%$ \\
explained by items & $67.6 \%$ & $3.2 \%$ \\
Raw unexplained & 21.5 & \\
variance (total) & $8.1 \%$ & \\
Unexplaned & 14.2 & \\
variance in 1st & $5.3 \%$ & \\
contrast & 6.9 & \\
Unexplaned & $2.6 \%$ & \\
variance in 2nd & 6.4 & \\
contrast & $2.4 \%$ & \\
Unexplaned & 5.8 & \\
variance in 3rd & $2.2 \%$ & \\
contrast & & \\
Unexplaned & & \\
variance in 4th & & \\
contrast & & \\
\hline & & \\
\hline
\end{tabular}




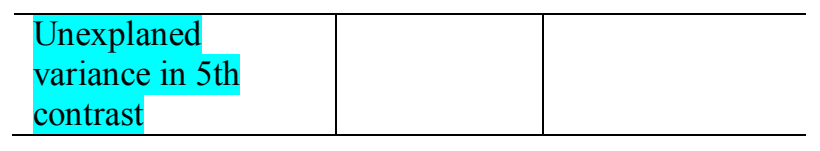

The magnitude data of the first residual factor using the Rasch factor can be determined easily as compared to other measurement model (Tennant \& Pallant,2006; Sick, 2011; Wright, 1999). Reckase (1979) accept raw variance explained by measures greater than $20 \%$ but Rasch requires $40 \%$ as an indicator of unidimensionality. Generally as shown in table 1 , it can be considered since the modeled variance is $32.4 \%$ and the unexplained variance is quite noisy at $8.1 \%$ nearing the limit of $15 \%$. Thus, further test need to be done to improve the uni-dimensionality of the instrument.

The next steps are by examining the redundancy or possible multi-collinearity through item pairs. It is important to note the local dependency specifies that the value of one data has no influence on another once the underlying data has been accounted (Wright, 1996). As such, data from this study were fitted to the model and tested for appropriate category ordering if local dependency and principal component analysis were done since this two methods are equally answered the unidimensionality and multicollinearity methods in classical test theory (Yen, 1993; Zenisky et al., 2003; Salzberger \& Sinkovics, 2006; Pallant et al., 2006).

Further investigation known as fit statistic being tested to further evaluate person's responses to test items to the model" (Boone \& Scantlebury, 2005). Bond and Fox (2007) reasoning of having fit statistics from the technical explanation as, "the use of chi-square fit statistic to determine how well any set of empirical data met the requirements of this model'. In addition Wright (1977) and Linacre (2002), recommended similar steps toward detecting the dissimilarity among items. It is important to identify how respondent's pattern accurately or predictably fit the model by converting the mean-square statistics to the normally-distributed $\mathrm{z}$ standardized. To abridge the findings, Azrilah (2010) recommended four (4) criteria as to check for any outliers or misfits data, as any misfits pattern to be considered are focused on the requirements given, that are:

(1) Point Measure Correlation:

(Pt-Mea Corr); $0.4<$ PT-Mea Corr value $<0.85$.

(2) Point Measure Correlation (PT-Mea Corr); gave a negative value (meaning that the person is predicted a misfit due to careless respond or guessing).

(3) Outfit Mean Square (MNSQ): $0.5<$ Outfit MNSQ value $<1.5$

(4) Outfit Z-Standard (Z-STD); $-2<$ Outfit Z-Std value $<+2$

If the items under investigation do not meet the above criteria thence, the items can be discarded due to poor quality fit.

\section{Conclusion}

Generally, the findings from the Rasch measurement model in answering the reliability, validity and the level of significance are totally different from the classical test theory (CTT) approach. In CTT, it is generally focused on items (or test) rather than persons or items independently (Bell, 1982). However, the Rasch model is concerned about what people do in testing or estimating the person's ability. This supports Andrich's (1982) argument on the shortfalls of CTT computation for Cronbach-alpha based on raw score as compared to Rasch analysis using the probabilistic model. Additionally, the observed variance among the person parameter estimates and the result thereof are used to construct measurement scales which yield a better value of reliability as compared to Cronbach alpha (KR-20). With the implementation of principal component analysis a total of 101 unfit items are discarded from the original 334 items. Further checking on the content validity shows that the person reliability and item reliability increase as compared to before the elimination is made.

\section{References}

Andrich, D. (1982). An Index of Person Separation in latent Trait Theory, the traditional KR-20 Index, and the Guttmen Scale Response Pattern, Education Research and Perspectives, 9 (1), 95-104.

Andrich, D. (1988). Rasch Models for Measurement, Newbury Park, CA:SAGE.

Ary, D., Jacobs, L.C. \& Razavieh, A. (2002). Introduction for research in education. Sixth Edition. Wadsworth Thomson Learning.

Azrilah, A.A. (2010). Rasch Model Fundamentals: Scale Construct and Measurement structure, Perpustakaan Negara Malaysia, Kuala Lumpur.

Bell, R.C. (1982). Person Fit and Person Reliability, Education Research and Perspectives, 9 (1), 105113.

Bond, T.G. \& Fox, C.M. (2007). Applying the Rasch Model : Fundamental measurement in the Human Sciences. Second Edition

Boone, W.J. \& Scantlebury, K. (2005). The role of Rasch Analysis when conducting science education research utilizing multiple-choice tests. Wiley InterScience, www.interscience.wiley.com, DOI 10.1002/sce.20106.

Fisher Jr., W.P. (2000). Theory, Instrumentation and Data, Rasch Measurement Transactions, 14 (3), 760.

Fisher, W.P., Jr. (2007). Rating Scale Instrument Criteria Quality Criteria. Rasch Measurement Transactions, 21 (1), 1095.

Fisher Jr., W.P. (2008). The Cash Value of Reliability, Rasch Measurement Transactions, 22 (1), 11581160.

Fisher Jr., W.P. (2010). The standard Model in the history of the Natural sciences, Econometrics, and 
the social sciences, Journal of Physics: Conference Series, 238 (2010), 012016.

Fisher Jr., W.P., Elbaum, B. \& Coulter, A. (2010). Reliability, Precision, and Measurement in the Context of data from Ability Tests, Surveys, and Assessments, Journal of Physics: Conference Series, 238 (2010), 012036.

Garson, G.D. 1998. Reliability analysis. Available at http://faculty.chass.ncsu.edu

/garson/PA765/reliab.htm.

Gliem, J. A., \& Gliem, R. R. (2003). Calculating, Interpreting, and Reporting Cronbach's Alpha Reliability Coefficient for Likert-Type Scales. Paper presented at the Midwest Research to Practice Conference in Adult, Continuing, and Community Education, Columbus, $\mathrm{OH}$.

Leedy, P. D., \& Ormrod, J. E. (2005). Practical research: Planning and design ( ${ }^{\text {th }}$ ed.). New Jersey: Prentice Hall.

Linacre, J.M. \& Wright, B.D. (1994). (Dichotomous Mean-Square) Chi-square Fit Statistics, Rasch Measurement Transactions, 8 (2), 360-363.

Linacre, J.M. (1994). Sample Size and Item Calibration (or Person Measure) Stability, Rasch Measurement Transactions, 7 (4), 328.

Linacre, J.M. (1996). True-score Reliability or Rasch Statistical Validity?, Rasch Measurement Transactions, 9 (4), 455.

Linacre, J.M. (1997). KR-20 or Rasch Reliability: Which Tells the "Truth", Rasch Measurement Transactions, $11(3)$.

Linacre, J.M. (2001). Generalizability Theory and Rasch Measurement, Rasch Measurement Transactions, 15 (1), 806-807.

Linacre, J.M. (2002). What do Infit and Outfit, MeanSquare and Standardized Mean?, Rasch Measurement Transactions, 16 (2), 878-879.

Linacre, J.M. (2003). Rasch Power Analysis: Size vs. Significance Chi-Square Fit Statistic, Rasch Measurement Transactions, 17 (1), 918-919.

Linacre, J.M. (2006). A User's Guide to WINSTEPS® MINISTEP Rasch-Model Computer Programs Program Manual 3.68.0. www.winsteps.com.

Linacre, J.M. (2007). Standard Errors and Reliabilities: Rasch and Raw Score, Rasch Measurement Transactions, 20 (4), 1086.

Linacre, J.M. (2008). The Expected Value of a pointBiserial (or Similar) Correlation, Rasch Measurement Transactions, 22 (1), 1154.

Onwuegbuzie, A.J. \& Daniel, L. (2002). Uses and misuses of the correlation coefficient. Research in the Schools, 9, 73-90.

Pagani, L. \& Zanarotti, M.C. (2010). Some Uses of Rasch Models Parameters in Customer Satisfaction Data Analysis. Quality Technology \& Quantitative Management, 7 (1), 83-95, 2010.

Pallant, J.F., Miller, R.L. \& Tennant, A. (2006). Evaluation of the Edinburgh Post Natal Depression Scale using Rasch Analysis. BMC Psychiatry, 28 (6).
Reckase, M.D. (1979). Unifactor latent trait models applied to multifactor tests: Results and

implications. Journal of Educational Statistics, 4, 207230.

Salzberger, T. \& Sinkovics, R.R. (2006). Reconsidering the problem of data equivalence in international marketing research - Contrasting approaches based on CFA and the Rasch model for measurement. International Marketing Review, 23 (4), 390-417.

Sekaran, U. (2003). Research Methods For Business: A Skill Building Approach. Fourth Edition. John Wiley $\&$ Sons, Inc.

Sick, J. (2011). Rasch Measurement and Factor Analysis, SHIKEN : JALT Testing \& Evaluation SIG Newsletter, 15 (1) March 2011, 15-17.

Tennant, A. \& Pallant, J.F. (2006). Unidimensionality matters (A tale of two Smiths?). Rasch Measurement Transaction, 20 (1) Summer, 1048-1051.

Yen, W.M. (1984). Effects of Local Item Dependence on the Fit and Equating Performance of the ThreeParameter Logistic Model, Applied Psychological Measurement, 8, 125-145.

Yen, W.M. (1993). Scaling Performance Strategies for Managing Local Item Dependence, Journal of Educational Measurement, 30 (3), Performance Assessment (Autumn, 1993), 187-213.

Wright, B.D. (1977). Solving measurement problems with the Rasch Model. Journal Of Educational Measurement, 14 (2), 97-116.

Wright, B.D. (1996). Local dependency, correlations and principal components. Rasch Measurement Transactions, 10 (3), 509-511.

Wright, B.D. (1997). Measurement for social science and education - A history of social science measurement. http://www.rasch.org/memo62.pdf.

Wright, B.D. (1999). Common sense for measurement. Rasch Measurement Transactions, 13 (3), 704.

Wright, B.D., Perkins, K. \& Dorsey, J.K. (2000). Rasch measurement instead of regression. Multiple Linear Regression Viewpoints, 26 (2), 36-41.

Zenisky, A. L., Hambelton, R. K. \& Sireci, S. G. (2003). Effects of local item dependence on the validity of IRT item, test and ability statistics. Association of American Medical Colleges (AAMC). http://www.aamc.org/students/mcat/research/monogr aph5.pdf.

Zikmund W., Babin, B., Carr. J. \& Griffin, M. (2010). Business research methods ( $8^{\text {th }}$ ed.). South-Western: Cengage Learning. 